\title{
Rancang Bangun Aplikasi Album Foto Digital 'Fotokita' dengan Penyimpanan Dinamis
}

\author{
Fadrian Merdianto, R.V. Hari Ginardi, dan Rizky Januar Akbar \\ Jurusan Teknik Informatika, Fakultas Teknologi Informasi, Institut Teknologi Sepuluh Nopember \\ (ITS) \\ Jl. Arief Rahman Hakim, Surabaya 60111 Indonesia \\ e-mail: hari@its.ac.id
}

\begin{abstract}
Abstrak-Semakin maraknya hobi untuk mendokumentasikan kegiatan dalam bentuk foto digital membuat setiap orang semakin tertarik untuk mengunggah foto hasil dokumentasinya ke dalam media-media tertentu. Fenomena tersebut akan menjadi lebih menarik dengan menyatukan dokumentasi tersebut ke dalam sebuah album, yang tentunya juga dalam bentuk digital. Aplikasi album digital dalam bentuk desktop dapat ditemukan pada aplikasi Fotokita. Dengan kondisi semakin maraknya kolektor foto, tentunya pengguna aplikasi Fotokita berkembang pesat. Dengan penggunaan aplikasi yang intensif tentu diperlukan penyimpanan yang dapat mengakomodasi bermacam gambar serta mampu mengakomodasi berbagai versi agar tidak ada kesalahan ketika membuka file. Pada tugas akhir ini dibuat aplikasi yang mampu mengakomodasi penyimpanan serta pembacaan file berdasarkan informasi metadata pada aplikasi Fotokita sesuai dengan hasil yang sama dengan aplikasi. Rancangan ini dapat mengakomodasi perubahan struktur file untuk mengantisipasi pemabaruan aplikasi dengan konsep Forward Compatibility dan Backward Compatibility.
\end{abstract}

Kata Kunci-Backward Compatibility, Forward Compatibility, foto digital, metadata

\section{PENDAHULUAN}

$\mathrm{F}$ ENOMENA semakin maraknya aktivitas pengabadian momen, dan diiringi dengan kebutuhan masyarakat, tentunya harus ada teknologi yang dapat membantu memudahkan proses tersebut. Beberapa solusi yang pernah ada belum maksimal, dikarenakan mayoritas solusi tersebut ada dalam bentuk online, sedangkan jaringan di Indonesia belum bisa dikatakan mampu untuk melakukan semua kegiatan dalam sistem online. Perlu adanya sistem yang memudahkan masyarakat untuk berkreasi menyusun hasil jepretan mereka secara standalone, agar pengerjaan tersebut berjalan stabil, dan tentunya perlu adanya tempat untuk memamerkan hasil karya masyarakat secara luas, sehingga perlu adanya sistem yang juga mendukung pertunjukan karya tersebut secara online.

Dengan berbagai struktur dalam buku tersebut, dan dengan kebutuhan bahwa dalam aplikasi tersebut harus dapat dengan baik tersinkronisasi ketika offline maupun online, tentunya dibutuhkan sebuah cara agar berbagai jenis kreasi pengguna tersebut dapat disimpan dalam sebuah file yang dapat digunakan kembali. Dalam penyimpanan file tersebut digunakan XML, sebuah bahasa markup untuk membuat dokumen markup keperluan pertukaran antara sistem yang berbeda. Dengan XML, banyak komponen yang dibutuhkan untuk membuat struktur yang baik agar dalam penyimpanannya, struktur-struktur file tersebut dapat disusun secara struktural.

\section{TINJAUAN PUSTAKA}

A. $X M L$

Sebuah bahasa markah untuk mendeskripsikan data. XML merupakan turunan (subset) atau versi ringkas dari SGML (Standard Generalized Markup Language). SGML sendiri merupakan sebuah standar ISO untuk format dokumen. XML dengan cepat diadopsi sebagai standar untuk pertukaran data, khususnya untuk penggunaan lintas aplikasi dan platform. Kelebihan dari XML adalah karakteristiknya yang extensible dan platform independen [1].

\section{B. XPath}

XPath merupakan bahasa query untuk memilih bagianbagian (node) dari sebuah dokumen XML. XPath juga dapat digunakan untuk menghitung nilai (contoh: string, angka atau boolean) dari isi dari sebuah dokumen XML. XPath distandarisasi oleh World Wide Web Consortium (W3C). Bahasa XPath dirancang berdasarkan struktur pohon dari dokumen XML, dan memiliki kemampuan untuk menavigasi struktur pohon tersebut serta memilih bagian-bagian dari dokumen XML berdasarkan berbagai macam kriteria [2].

\section{Java JAXB 2.0}

Java Architecture for XML Binding (JAXB) merupakan cara cepat dan nyaman untuk mengikat skema XML dan representasi Jawa, sehingga mudah bagi pengembang Java untuk menggabungkan data XML dan fungsi pengolahan dalam aplikasi Java. Sebagai bagian dari proses ini, JAXB menyediakan metode untuk unmarshalling (membaca) XML dokumen ke dalam Java, dan kemudian menyusun pohon (menulis) konten Java kembali ke dokumen XML. Komponen yang menyusun implementasi JAXB dapat dilihat pada Gambar 1. Keterangan dari Gambar 1 adalah sebagai berikut [3].

- Schema compiler: Membungkus skema sumber ke dalam sebuah elemen skema turunan program.

- Schema generator: Memetakan elemen-elemen yang telah 
dibuat berdasarkan program ke dalam skema turunan.

- Binding runtime frameworks: menyediakan fungsi unmarshalling (membaca) dan marshalling (menulis) dokumen.

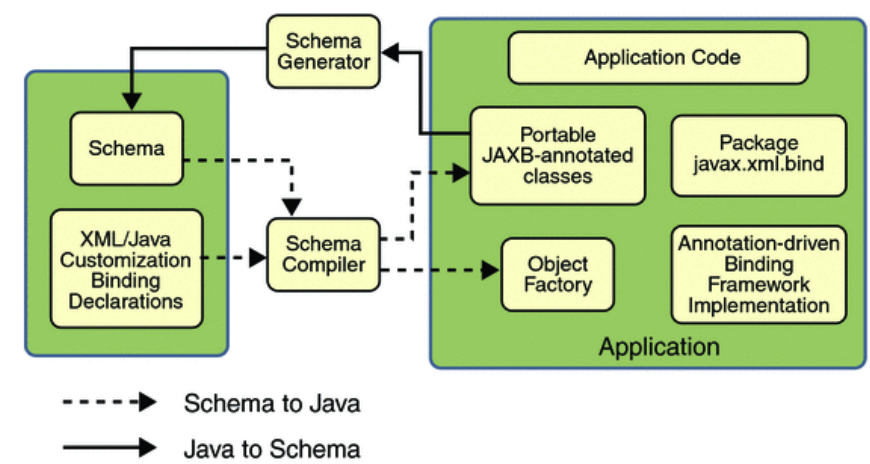

Gambar 1. Arsitektur JAXB

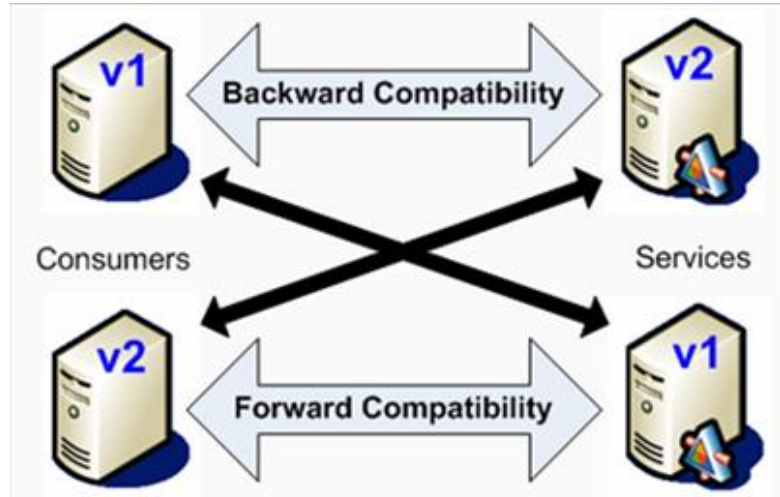

Gambar 2. Skema kerja Forward Compatibility dan Backward Compatibility

\section{Skema XML}

Skema XML merupakan sebuah bahasa untuk mengekspresikan batasan-batasan yang dapat ditentukan untuk sebuah dokumen XML. Ada banyak jenis bahasa skema XML yang dapat digunakan dan tersebar dapat digunakan, yang paling umum diantaranya adalah Document Type Definitions (DTDs), Relax-NG, Schematron, dan W3C XSD (XML Schema Definition). Skema XML dapat digunakan sebagai berikut [4] [5]:

- Mendefinisikan daftar elemen yang digunakan.

- Untuk mengasosiasikan tipe data.

- Memberikan batasan atribut dan elemen yang dapat diletakkan dalam suatu node.

- Memudahkan manusia untuk membaca dokumen XML.

- Sebagai bentuk normal dari definisi dokumen XML satu dengan yang lainnya.

\section{E. Forward Compatibility}

Forward Compatibility merupakan kemampuan sebuah sistem untuk menerima, membaca, melihat, ataupun melakukan fitur pada sistem baru yang memiliki komponen berbeda, meskipun tidak seluruh fitur dari sistem yang baru tersebut diimplementasikan. Contoh dari Forward Compatibility adalah aplikasi Microsoft Office Word 2003, yang dapat membuka file aplikasi Microsoft Office Word
2007, namun tidak mengimplementasi beberapa fitur seperti sitasi, persamaan secara optimal.

Tabel 1.

Objek penyusun metadata Fotokita

\begin{tabular}{|c|c|c|}
\hline No & Objek & Keterangan \\
\hline 1. & Judul Proyek & Judul Proyek yang dibuat \\
\hline 2. & Versi Aplikasi & $\begin{array}{l}\text { Versi Aplikasi pada saat pembuatan } \\
\text { proyek }\end{array}$ \\
\hline 3. & Pembuat Proyek & Pembuat proyek \\
\hline 4. & Jumlah Halaman & $\begin{array}{l}\text { Banyaknya halaman yang dibuat dalam } \\
\text { satu proyek }\end{array}$ \\
\hline 5. & $\begin{array}{l}\text { Tanggal Pembuatan } \\
\text { Proyek }\end{array}$ & Tanggal pembuatan pertama proyek \\
\hline 6. & $\begin{array}{l}\text { Pengubahan Terakhir } \\
\text { Proyek }\end{array}$ & Tanggal pengubahan terakhir proyek \\
\hline 7. & Ukuran Halaman & Ukuran halaman proyek \\
\hline 8. & Gambar Foto & Gambar foto yang disusun \\
\hline 9. & Frame & Frame penampung gambar \\
\hline 10. & Teks & $\begin{array}{l}\text { Teks yang ditambahkan untuk } \\
\text { menambah keterangan gambar objek }\end{array}$ \\
\hline
\end{tabular}

F. Backward Compatibility

Backward Compatibility merupakan kemampuan sebuah sistem baru untuk menerima, membaca, melihat, dan mengimplementasi fitur yang ada pada sistem versi sebelumnya. Contoh implementasi Backward Compatibility antara lain adalah perangkat PlayStation 3 dapat memainkan permainan yang ada pada PlayStation 2. Perbedaan antara Forward Compatibility dan Backward Compatibility dapat dilihat pada Gambar 2 [5] [6].

\section{PERANCANGAN SISTEM}

\section{A. Analisis}

Sistem yang dibuat merupakan implementasi dari aplikasi berbasis desktop Fotokita [7]. Penyimpanan dari aplikasi tersebut disimpan menjadi sebuah file objek .fbk yang tersusun dari susunan metadata. File yang telah dibuat oleh pengguna dapat dibuka kembali oleh aplikasi di lain waktu. Selain itu, proyek juga dapat diunggah ke dalam aplikasi katalog web untuk nantinya dapat diproses dan dicetak sesuai kebutuhan pengguna.

\section{B. Analisis Desain Aplikasi}

Berdasarkan analisis terhadap aplikasi editor Fotokita, disusun objek yang dibutuhkan agar kebutuhan pada aplikasi desktop dan web dapat diakomodasi [8]. Setiap file yang disusun dalam penyimpanan pada aplikasi ini memenuhi beberapa objek yang dijabarkan pada Tabel 1.

\section{Perancangan Struktur File}

File yang disimpan oleh aplikasi editor dibungkus dalam format ekstensi .fbk. Struktur file dapat dilihat pada Gambar 3. Di dalam bungkus tersebut terdapat dua elemen, yaitu folder temp dan file main.xml. File main.xml merupakan file utama yang berisi struktur xml yang digunakan untuk membungkus maupun membuka file dengan ekstensi .fbk. Di dalam folder temp terdapat folder pic dan frame, yang menampung gambar yang disimpan dan dibuka oleh aplikasi. Gambar yang disimpan di dalam folder pic dan frame merupakan file binary 
yang nantinya akan langusng dimuat dan diimplementasikan pada editor ketika file tersebut dibuka oleh aplikasi.

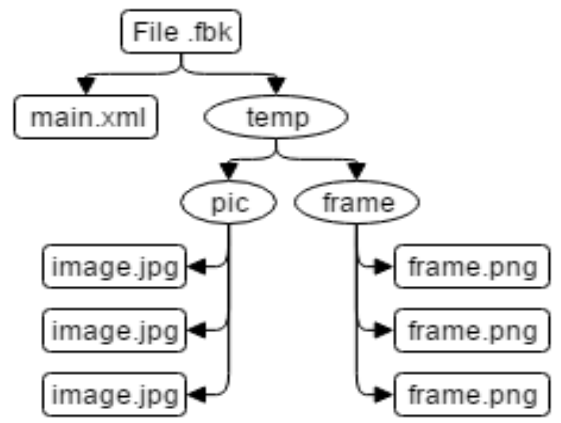

Gambar 3. Struktur file .fbk

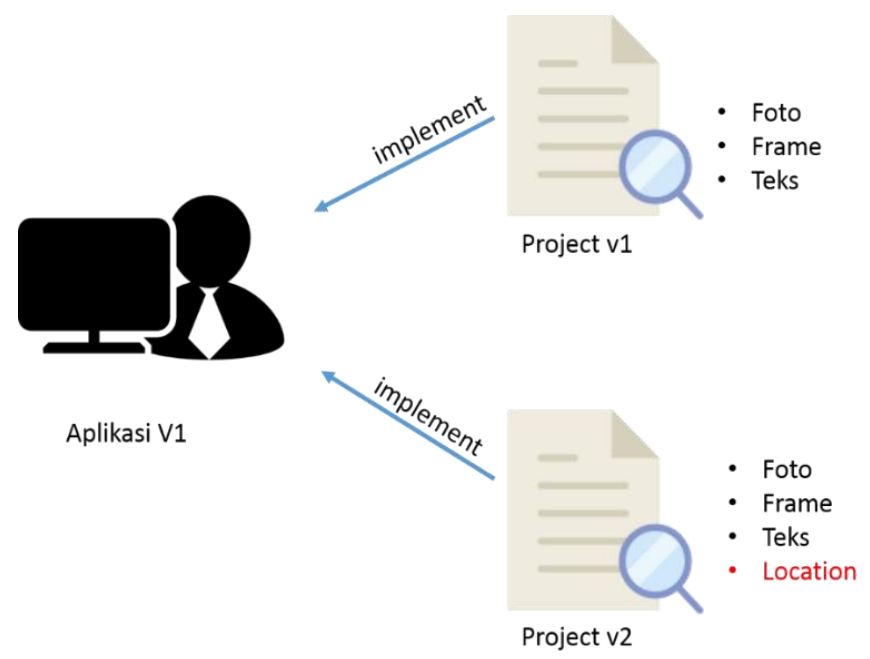

Gambar 4. Perancangan skema Forward Compatibility

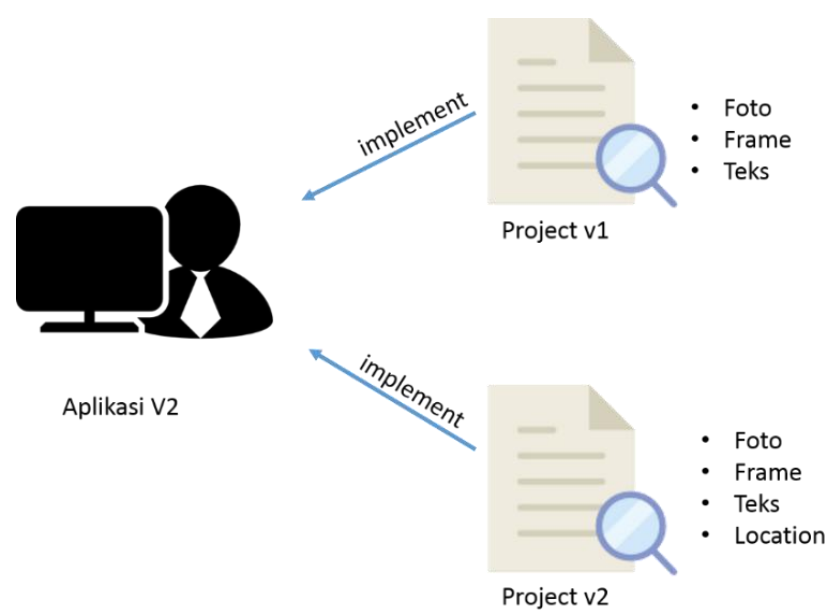

Gambar 5. Perancangan skema Backward Compatibility
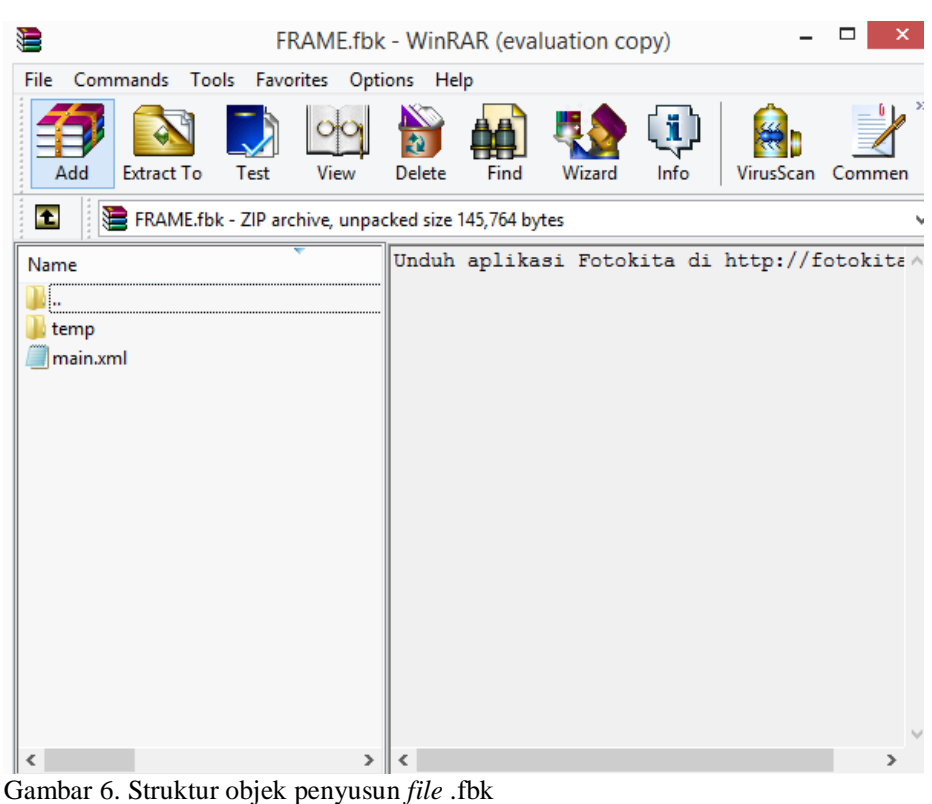

Gambar 6. Struktur objek penyusun file .fbk

Tabel 2 .

Spesifikasi lingkungan pengujian

\begin{tabular}{ll}
\hline \hline Spesifikasi & Deskripsi \\
\hline CPU & Intel ${ }^{\circledR}$ Core TM i7-3612QM CPU @ 2.10 GHz \\
RAM & $8.00 \mathrm{~GB}$ \\
Sistem Operasi & Windows 8.1 Embedded Industry Pro 64 bit \\
\hline \hline
\end{tabular}

D. Perancangan Skema Forward Compatibility dan Backward Compatibility

Perancangan skema forward compatibiliy mengakomodasi kemungkinan sebuah aplikasi versi lebih rendah membaca file yang disimpan dalam versi lebih tinggi. Karena sistem aplikasi versi lebih rendah tidak memiliki fitur yang sama persis dengan sistem aplikasi versi lebih tinggi, maka diperlukan sebuah skema yang mampu mengantisipasi kesalahan keadaan tersebut. Pada umumnya, kondisi ini diantisipasi dengan tidak mengimplementasi fitur dari file versi lebih tinggi yang tidak ada pada sistem aplikasi versi lebih rendah. Keadaan tersebut dapat dilihat pada Gambar 4. Pada Gambar 4, fitur location pada versi 2 berwarna merah karena fitur tersebut tidak diimplementasikan pada aplikasi versi 1 .

Perancangan skema backward compatibiliy mengakomodasi kemungkinan sebuah aplikasi versi lebih tinggi membaca file yang disimpan dalam versi lebih rendah. Pada kasus ini, sistem aplikasi baru memiliki fitur yang lebih banyak dari file versi lebih rendah. Karena sistem aplikasi versi lebih tinggi dapat mengakomodasi fitur yang terdapat pada file versi lebih rendah, maka sistem aplikasi versi lebih tinggi dapat mengimplementasi seluruh fitur yang terdapat pada file versinya maupun lebih rendah, sehingga pada skema Backward Compatibility ini tidak ada perubahan terhadap file yang diimplementasikan dalam aplikasi. Keadaan tersebut dapat dilihat pada Gambar 5. 
Tabel 3.

Daftar pengujian

\begin{tabular}{ccll}
\hline \hline No & $\begin{array}{c}\text { Kode } \\
\text { Pengujian }\end{array}$ & \multicolumn{1}{c}{ Keterangan } \\
\hline 1 & UJ-001 & Pengujian Menyimpan File & \\
2 & UJ-002 & $\begin{array}{l}\text { Pengujian Membaca File dengan Versi } \\
\text { Aplikasi yang sama }\end{array}$ \\
3 & UJ-003 & Pengujian Menyimpan File yang Telah diubah \\
4 & UJ-004 & Pengujian Forward Compatibility \\
5 & UJ-005 & Pengujian Backward Compatibility & \\
\hline \hline
\end{tabular}

Tabel 4.

Hasil pengujian

\begin{tabular}{cccc}
\hline \hline No & Pengujian & Berhasil & Tingkat keberhasilan (\%) \\
\hline 1 & UJ-001 & 10 & $100 \%$ \\
2 & UJ-002 & 10 & $100 \%$ \\
3 & UJ-003 & 10 & $100 \%$ \\
4 & UJ-004 & 10 & $100 \%$ \\
5 & UJ-005 & 10 & $100 \%$ \\
\hline \hline
\end{tabular}

\section{IMPLEMENTASI}

\section{A. Lingkungan Implementasi}

Dalam merancang perangkat lunak ini digunakan beberapa perangkat pendukung yang terdiri dari perangkat keras dan perangkat lunak. Spesifikasi perangkat keras yang digunakan dalam membangun aplikasi dituliskan pada Tabel 2.

Perangkat lunak yang digunakan untuk membuat aplikasi Fotokita antara lain sebagai berikut:

- Eclipse Luna, digunakan sebagai IDE.

- StarUML, digunakan untuk merancang diagram kelas.

\section{B. Implementasi Struktur File}

Struktur file yang diimplementasikan sesuai dengan perancangan ada pada Gambar 6. menunjukkan struktur utama file .fbk yang berisi file main.xml serta folder temp. Folder temp berisi foto dan frame berupa file binary yang akan diimplementasikan secara langsung pada aplikasi editor Fotokita.

\section{Implementasi Forward dan Backward Compatibility}

Implementasi penggunaan Forward Compatibility dilakukan dengan menambah elemen pada file berekstensi .fbk yang telah dibuat. Penambahan elemen baru adalah elemen location yang berada pada elemen anakan dari elemen fotokita. Penambahan tersebut memiliki struktur yang sama dengan elemen yang ada pada versi lebih tinggi.

Implementasi penggunaan Backward Compatibility dilakukan dengan menyimpan file yang tidak mengimplementasikan elemen teks. Pengembangan versi lebih rendah tidak mempunyai elemen pada struktur model metadata-nya.

\section{UJI COBA DAN HASIL}

Lingkungan pengujian adalah lingkungan, baik perangkat keras maupun perangkat lunak tempat pengujian sistem dilakukan. Pengujian untuk rancang bangun penyimpanan dinamis dilakukan pada komputer dengan spesifikasi ditunjukkan pada Tabel 2. Pengujian dilakukan dengan beberapa skenario yang dijelaskan pada Tabel 3. Pengujian dilakukan sebanyak 10 kali pada masing-masing skenario.
Tabel 4 menunjukkan hasil pengujian, di mana hasil dari seluruh skenario yang dilakukan berhasil sesuai skenario.

\section{KESIMPULAN}

Dari hasil pengamatan selama proses perancangan, implementasi, dan pengujian perangkat lunak yang dilakukan, dapat diambil kesimpulan sebagai berikut.

1. Metadata XML dapat mengakomodasi penyimpanan file aplikasi Fotokita.

2. Penggunaan forward dan backward compatibiliy sangat penting untuk aplikasi yang bersifat agile, agar dalam setiap versi yang berbeda, aplikasi tetap dapat mengeksekusi file.

\section{DAFTAR PUSTAKA}

[1] Liam, "Extensible Markup Language (XML)," w3c, 19 Mei 2015. [Online]. Available: http://www.w3.org/XML/. [Accessed 23 November 2015].

[2] w3c, "XML Path Language (XPath)," w3c, [Online]. Available: http://www.w3.org/TR/xpath/. [Accessed 23 November 2015].

[3] Oracle, https://docs.oracle.com/javase/tutorial/jaxb/intro/arch.html, [Online]. Available:

https://docs.oracle.com/javase/tutorial/jaxb/intro/arch.html. [Accessed 22 Maret 2016].

[4] w3schools, "XML Schema," [Online]. Available: http://www.w3schools.com/xml/schema_intro.asp. [Accessed 10 Mei 2016].

[5] Ullman, Jeffrey D.; Widom, Jennifer, A First Course In Database System 3rd Edition, New Jersey: Pearson Education Inc, 2007.

[6] Microsoft, "Microsoft MSDN," Microsoft, 2011. [Online]. Available: https://msdn.microsoft.com/enus/library/ff649901.aspx. [Accessed 22 Maret 2015].

[7] M. A. Ridwan, "Rancang Bangun Aplikasi Editor Album Foto Digital 'Fotokita' berbasis Desktop," Surabaya, 2016.

[8] D. Siahaan, Analisa Kebutuhan dalam Rekayasa Perangkat Lunak, Yogyakarta: Andi, 2012. 